\title{
O RESGATE DO HOMEM MULTIDIMENSIONAL EM MUNDO UNIDIMENSIONAL
}

\section{Rescuing the multi-dimensional man in an one-dimensional world}

\author{
Nilton Maurício Martins Torquato ${ }^{1}$
}

\section{Resumo}

Em uma sociedade em que o consumo passou a ser a essência do esforço humano, a desumanização deste ser traz consigo conseqüências capazes de desenvolver um efeito altamente destrutivo que redunda em uma constante inadequação dele frente às necessidades que lhe apresentam. A redescoberta de si mesmo advém por meio do reencontro com a integralidade deste ser, desenvolvida pela redescoberta do belo e do estético, do emocional e relacional e do espiritual e transcendente. A aplicação desta reconstrução do ser humano atinge a produtividade a partir da integralização do profissional envolvido, objetivando sua realização interior e sua superação exterior. A partir disto, o ser humano, que se tornara unidimensional, reencontra seu paradigma identitário e compreende-se enquanto ser social. Redescobre-se humano e humaniza suas relações.

Palavras-chave: Unidimensional; Espiritualidade; Identidade; Sociedade; Emocional.

\section{Abstract}

In a society where consumption is the essence of human effort, the dehumanization of human kind brings along consequences which can develop highly destructive effect which ends up in a constant inadequacy of human beings when they have to face the needs which are prevailing. The re-discovery of oneself, comes through, once again, meeting with the fullness of his own being, developpped through the rediscovery of beauty and the aesthetic; through the emotional and the relational; and through the spiritual and the transcendental. The application of such reconstruction of the human being reaches productivity when the full integration of him/her has begun. Starting there, the human being who had become one-dimensional, rediscovers his identity paradigm and understands himself inlaid in this society. He feels human and humanizes his relationships.

Keywords: One-dimensional; Spirituality; Identity; Society; Emotional.

${ }^{1}$ Teólogo, professor de história da Igreja no SEMIBC. Torquato@bol.com.br 


\section{Justificativa}

A sociedade em que vivemos está passando por mutações seqüenciais, o que determina grande dificuldade em adaptação do ser humano. As funções produtivas ligadas à indústria de serviços e de produção são sempre exigidas como forma de garantir a perpetuação da estrutura ora vigente.

Castells observa que a indústria de serviços será a principal realidade neste século XXI, acompanhada pela ausência de segurança no meio de trabalho. Isto se torna frontalmente oposto à tese de qualidade total no atendimento ao cliente, sendo este fator diferencial na escolha de uma determinada empresa ou estabelecimento para consumo. Segue-se que este ser humano destituído de certezas necessita resgatar valores considerados seguros no passado, de forma a reencontrar seu ser e desenvolver-se profissional e socialmente, buscando um trabalhar mais criativo e feliz. Para este resgate, compreendo ser necessária a reconstrução do homem multidimensional perdido através do tempo, sufocado pelas pressões e imposições da vida adulta em que tramita.

Este desfigurar encontrou no positivismo seu maior expoente, visto que a repressão perpassa seu imaginário impedindo-o de interagir com o meio que o circunda e, mediante a tese de que a lógica pode explicar tudo, destruiu os sonhos e o mundo do imaginário religioso. É claro que esta ação não ocorreu sem dano para a inter-relação com os demais personagens envolvidos na sociedade, gerando rupturas que derivam no individualismo, na destruição dos relacionamentos, na perda da criatividade e do senso de arte e estética. O consumo ditado pela mídia torna-se esteticamente aceitável, mesmo que em sua essência seja a expressão do antiestético, no padrão do belo inerente ao ser.

A proposta deste trabalho é demonstrar que a recuperação deste ser é possível mediante a reconstrução das bases em que se estrutura, buscando um reencontro com seu "eu" multidimensional, apoiado no reencontro com a psique e a alma. Para tal, propõe-se que o reencontro com o emocional e o exercício espiritual sejam alvo de incentivo por parte da empresa, como forma de atingir um melhor resultado do funcionário, além de uma satisfação maior com o trabalho desempenhado.

\section{Introdução}

O positivismo trouxe consigo a possibilidade de atingir o maior crescimento que o ser humano já experimentara em toda a história da humanidade. A busca pelo conhecimento trouxe à humanidade um contingente de 
informações que inviabilizam qualquer um a tornar-se conhecedor de sequer um por cento destas informações. Estas informações permitiram um desenvolvimento tecnológico nunca antes experimentado, com uma acumulação de capitais espantosa. Esta acumulação permitiu a formação de conglomerados industriais e comerciais capazes de tramitar entre as nações e até sobre elas. Estas acumulações encontram na sociedade em rede sua concretização e reprodução, tornando a empresa um setor sem pátria e volatilizando o capital de forma a movimentar-se com a velocidade da internet.

Esta transformação social observada trouxe consigo a possibilidade de ampliação da vida humana de forma indefinida, levantando questões éticas até então desconhecidas. Eutanásia, reprodução assistida, clonagem, células tronco, entre outros, tomaram as discussões daquilo que era apenas um novo campo do conhecimento humano. As distorções na distribuição dos recursos implementaram várias questões quanto à viabilidade da tecnologia em áreas específicas do planeta em que nem as necessidades alimentares e sanitárias básicas são providas. Já é possível enviar espaçonaves terrestres para além do sistema solar, investindo-se milhões de dólares, mas questões humanitárias ainda não contam com recursos financeiros e tecnológicos capazes de minorálas e, até, extingui-las.

A visão apregoada pelo positivismo excluiu do ser humano partes importantes para a sua própria compreensão. Tudo se tornou cientificamente explicável, mas esvaziou a possibilidade de compreensão da complexidade da existência humana. O ser humano tornou-se como um objeto de laboratório, capaz de ser analisado, medido, estudado, usado e descartado. Quase um ser sem alma. A revolução industrial, fruto desta visão positivista, foi marcada por este ponto de vista, presente nas obras de Thomas Malthus e David Ricardo. A crítica desta forma de observar o ser humano foi alvo de ideologias que marcaram o século XX, gerando os antagonismos entre o mundo comunista e capitalista. Todos estes antagonismos esqueceram-se de levar em conta o ser humano real, denúncia muito bem levantada na obra cinematográfica de Charles Chaplin "Tempos Modernos". O homem tornou-se unidimensional ${ }^{2}$ e com isto atraiu para si doenças e frustrações que não podem ser compensadas mediante um consumismo mais exacerbado. "Estabelecida a lógica do lucro, todas as coisas - da talidomida ao napalm - se transformaram em mercadorias, inclusive o operário" (ALVES, 1989, p. 77). Este desequilíbrio interno se expressa externamente por uma atitude externa que deriva em comportamentos que geram transtornos sociais e interiores, conduzindo a uma crescente perda de eficiência e criatividade no trabalho. A depressão, o estresse e o uso de dro-

2 Neste caso faço uso de um conceito de Marcuse, indicando que o ser humano desumanizase ao transformar-se em uma simples máquina produtiva, com isto perde seu equilíbrio.

Revista Diálogo Educacional, Curitiba, v. 6, n.17, p. 139-148, jan./abr. 2006. 
gas, lícitas ou ilícitas, já são causas de afastamento de trabalho reconhecidas pela Organização Mundial de Saúde.

O homem vem usando a natureza como se esta fosse uma fonte inesgotável de recursos. Dentro desta ótica, já existe o debate quanto aos efeitos da poluição sobre o planeta e, em uma instância mais profunda, sobre o ser humano. O crescimento tecnológico e industrial tende a esbarrar em sua própria voracidade, tornando o estado de bem-estar tecnológico inviável em algumas décadas.

Torna-se necessária uma nova abordagem sobre o ser humano, capaz de torná-lo integrado ao meio em que vive, conduzindo-o a uma harmonia interior e exterior. A própria redução da violência não pode ser construída apenas pelo uso dela. O ser humano necessita de um reencontro consigo mesmo e com o seu próximo, sob pena de conduzir o individualismo rumo à própria destruição do indivíduo.

No caminho para esta reconstrução, trilhei algumas idéias esboçadas por autores como Herbert Marcuse, no que tange aos aspectos emocionais e cognitivos do ser humano; Manuel de Castells, em sua análise sobre a identidade em um mundo globalizado, onde ele indica inclusive a religião como forma deste resgate; Esa Mangeloja quanto ao aspecto religioso integrado à produção e Chiara Lubich e seu conceito de espiritualidade que transcende o universo religioso e se propaga pelo social.

Por este motivo, decidiu-se neste texto recobrar as questões relativas ao universo religioso ${ }^{3}$ que corre e percorre o mundo produtivo cotidiano, influenciando e se deixando influenciar por aqueles que vivem nas cadeias produtivas de nossa sociedade. Busca esta obra levantar o fato de que o ser humano necessita de representações religiosas capazes de dar sustentação emocional e ética de forma a transformá-lo em alguém ainda mais ativo e produtivo, integrado e integrador social, mais feliz e realizado.

Não parto da visão de que o espaço de trabalho deva ser transformado em um local de prática religiosa, mas que este espaço incentive a prática religiosa de seus empregados, levando-os a pôr em prática os ensinamentos recebidos de forma a potencializar o ambiente de trabalho.

Dentro desta visão, compreendo o ser como um todo, portanto o emocional relaciona-se com o religioso na busca do belo e da realização. Tomo por base a visão de Boff, que o belo é a expressão máxima do universo religioso. Sendo o belo percebido pelo emocional, compreendo que a sua observação somente pode ser completa mediante o resgate da múltipla dimensionalidade do ser.

Não cabe a este trabalho julgar entre grupamentos religiosos ou aspectos teológicos. Compreendo religião dentro do amplo espectro de representações religiosas encontráveis ao redor do mundo, não cabendo aqui qualquer senso crítico ou discriminatório sobre elas. 


\section{0 ser multidimensional}

Ao redigir sua obra "Eros e Civilização", Herbert Marcuse busca compreender este aspecto positivista da humanidade que, em última instância, estava conduzindo o ser humano a um conflito com seu "Eu" interior. "Como a sociedade afluente depende cada vez mais da ininterrupta produção e consumo do supérfluo, dos novos inventos, do obsolentismo planejado e dos meios de destruição, os indivíduos têm de adaptar-se a esses requisitos de um modo que excede os caminhos tradicionais" (MARCUSE, 1999, p. 13). Este método de controle que conduz o ser humano à perpetuação de seu meio de vida priva-o da liberdade e o conduz a uma visão utilitária do si próprio, desfigurando-o rumo à "coisificação". A esta forma de controle estabelecido, o autor denomina princípio de realidade, que na sociedade de consumo encontra-se intimamente ligada ao princípio de desempenho.

O desempenho tem sido o alvo da produtividade, onde o objetivo está ancorado na ampliação da quantidade de produtos aliada ao consumo constante, levando o ser humano a canalizar seu Eros em direção ao objeto consumido, desfocando-o de um prazer capaz de suprir à sua necessidade real. Torna o Eros um fator destrutivo. Faz-se desta forma possível construir um ser humano desumanizado. Este ser humano é cognominado por Marcuse como um ser unidimensional. "Na sociedade tecnológica totalitária, a liberdade só pode ser pensada como autonomia em relação ao aparato como um todo e isso inclui a liberdade de reduzi-lo ou reconstrú-lo como um todo com vistas à satisfação da luta pela existência, da redescoberta da paz, da felicidade" (MARCUSE, 1997, p. 45). Esta felicidade é percebida pelo autor como o reencontro com aquilo que permeia o ser em seu aspecto mais invisível, suas emoções. Estas emoções encontram-se intimamente atreladas à pessoa, mesmo quando busca racionalizá-las. "A prosperidade apresenta-se, cada vez mais, como um pré-requisito e um produto marginal de uma produtividade auto-impulsionada, em constante busca de novas saídas para o consumo e a destruição, no espaço exterior e interior, embora seja impedida de "extravasar' nas áreas de miséria - tanto as internas como as externas" (MARCUSE, 1999, p.15). Estas misérias derivam de um estado reprimido em que o ser humano desenvolveu um ascetismo do mundo interior, conduzindo a uma dominação insana do desejo interior pelo anseio consumista exterior.

Outro aspecto interessante a notarmos é que este ser humano possui outras representações mentais que superam a lógica impressa em nossa sociedade. Manuel de Castells indica estas representações como advindas de nossa necessidade de encontro com a identidade própria. Esta identidade manifesta-se em formas diferentes a partir de representações mentais que não podem ser explicadas apenas no mundo da lógica e da produção. Este ser huma- 
no, de quem é cobrada a produtividade e oferecido o consumo irrestrito, precisa encontrar sua própria razão de ser para não se perder frente à ditadura da modernidade que se lhe impõe. A religião é descrita como forma de reagrupamento social inter-relacionado à questão de identidade (CASTELLS, 2000).

Esta identidade pode ser de legitimadora, de resistência ou de projeto, portanto afetando diretamente as sociedades por ela influenciadas. Em seus livros, ele ressalta que em um mundo globalizado torna-se imperativo perceber aquilo que o diferencia para, enfim, perceber a si próprio. Nossas sociedades estão cada vez mais estruturadas em uma oposição bipolar entre a Rede e o Ser (CASTELLS, 1999, p. 23).

Dentre as representações mentais encontram-se aquelas que pertencem ao universo religioso. Já Max Weber havia ressaltado a influência da religião na produção capitalista (WEBBER, 2003). Em sua obra, ele ressalta como o protestantismo calvinista criou as condições favoráveis para a acumulação de recursos necessários à estruturação do capitalismo.

O que interessa a este escrito não é a condição de verdade das afirmações religiosas que estuda, mas a relação que mantêm essas afirmações, esses enunciados com o tipo de sociedade ou de cultura que os explicam. Logo, na inter-relação entre igreja e sociedade observa-se uma reciprocidade de influência mediante a cosmovisão dos personagens que tramitam entre e em ambos espaços.

Refletindo sobre o fenômeno religioso, Castells o explica mediante a ótica da construção de identidades que

o medo da morte, a dor da vida, precisam de Deus e da fé n'Ele, sejam quais forem suas manifestações, para que as pessoas sigam vivendo. (...) Neste mundo de mudanças confusas e incontroladas, as pessoas tendem a reagrupar-se em torno de identidades primárias: religiosas, étnicas, territoriais, nacionais. (...) Cada vez mais, as pessoas organizam seu significado não em torno do que fazem, mas com base no que são ou acreditam que são (CASTELLS, 2000, p. 23; 29).

Ele compreende que é possível uma leitura significativa de nossa sociedade hodierna sob o prisma da religião, mesmo que fundamentalista, pois esta fornece o discurso imprescindível para a reafirmação do ser, mediante suas múltiplas identidades. Esta visão leva a uma reflexão sobre o papel da religião no contexto histórico mundial, bem como nos aspectos ligados à produtividade, visto que a pessoa responsável pela produção é alguém que se observa vivendo dentro de aspectos ligados ao espiritual. 


\section{Desenvolvendo o homem multidimensional no exercício religioso}

"Instituições ${ }^{4}$ morais e éticas afetam o desenvolvimento econômico, como, por exemplo, confiança e honestidade são requerimentos essenciais para a emergência de sistemas econômicos" (MANGELOJA, [2004], p. 2). Esta afirmação nos conduz a uma possibilidade de compreensão da inter-relação entre o universo religioso e o mundo produtivo que o rodeia. Em um mundo que tenta banir a religião para um passado mitológico humano, estas representações da ausência tomam um papel fundamental para a própria compreensão das relações sociais em que os sujeitos encontram-se tecidos.

Sua extirpação somente promove o aparecimento dos fundamentalismos, tais como trincheiras de sobrevivência em uma sociedade que baniu o explicável pelo adquirível. "É aqui que surge a religião, teia de símbolos, rede de desejos, confissão da espera, horizonte dos horizontes, a mais fantástica e pretensiosa tentativa de transubstanciar a natureza" (ALVES, 1989, p. 22). Este é um aspecto bastante ressaltado por Rubem Alves ao notar que até o ateísmo é uma forma de observar-se o religioso, por ser construído sob as bases teóricas da religião. Portanto, o homem relaciona-se com a religião em todos os processos mentais em que se expõe. Cabe a este entender que seus conceitos necessitam de ser entendidos e aplicados no âmbito da prática.

Dentro deste aspecto, é importante ressaltar que a religião traz consigo um código de conduta que conduz, aqueles que a praticam seriamente, a uma forma de comportamento compatível com um viver social mais adequado, auxiliando na perpetuação social e econômica. "No mesmo momento a religião traz melhores níveis de saúde (desencorajando atividades que considera 'pecaminosas' como uso de drogas, sobre-alimentação, sexo desenfreado, álcool, etc.). Um alto nível de saúde na sociedade permite um crescimento da produtividade por meio de uma força de trabalho mais eficiente" (MANGELOJA, [2004], p. 6). Uma melhor expectativa de vida traduz-se em uma vida melhor e mais longívaga. Por outro lado, a religião, quando não consumida pelo fundamentalismo, tem demonstrado ser mais aberta a uma atitude positiva para com o próximo, principalmente em relação à alteridade. "A religião busca aumentar o grau de confiança e reduzir os níveis de corrupção e da atividade criminal, aumentar a abertura das nações quanto aos estrangeiros, tornando a economia mais aberta aos investimentos transnacionais e à empregabilidade" (Ibid, p. 6).

A religião traz consigo, ainda, a possibilidade de uma vida menos estressante e ansiosa. Não raramente é no âmbito religioso que as pessoas

4 Os textos pesquisados em outras línguas, quando citados nesta obra, serão traduzidos pelo autor deste texto, a fim de facilitar a leitura.

Revista Diálogo Educacional, Curitiba, v. 6, n.17, p. 139-148, jan./abr. 2006. 
encontram seu único espaço de consolo e abrigo. Isto é notado pelo fato de a religião ser a única instituição social capaz de perpassar todos os níveis sociais e culturais de uma sociedade, fornecendo apoio e atendimento até em ambientes insalubres em que a máquina do estado não consegue chegar ${ }^{5}$. Para Souza (2004)

A religião é, antes de tudo, uma construção sócio-cultural. Portanto, discutir religião é discutir transformações sociais, relações de poder, de classe, de gênero, de raça/etnia; é adentrar num complexo sistema de trocas simbólicas, de jogos de interesse, na dinâmica da oferta e da procura; é deparar-se com um sistema sócio-cultural permanentemente redesenhado que permanentemente redesenha as sociedades.

A religião, em seu estado mais importante que o interior da pessoa, deve ser incentivada e motivada a uma experiência de práxis. Esta práxis deve ser perpassada pela compreensão do outro, enquanto figura religiosa aparentemente antagônica, a fim de que não se aproxime do fundamentalismo fisiológico, cuja única função é a de se autopropagar.

No caso da religião, um católico, um protestante, um espírita, um judeu, um muçulmano ou um ateu, mesmo que nunca falem em religião, deixarão transpirar suas convicções. Então, é muito melhor tratar da questão, discutindo com respeito as diferentes correntes religiosas, pois que a religião faz parte essencial das vidas da maioria dos seres humanos, do que bani-la (INCONTRI, 2005).

Logo, o exercício responsável dela pode auxiliar na reconstrução do ser, tornando-o mais humano e apaixonado pelo que é e faz, direcionando sua ação para a coletividade, percebendo o outro, compreendendo-se como um ser imerso em uma teia de correlações.

Até hoje as espiritualidades foram quase sempre individuais; contudo nunca são exclusivamente assim, pois sempre influem no Corpo místico. Porém chegou a hora, como dizia Paulo VI, da santidade de povo, não só de um santo individual. Portanto, a nossa característica evangélica é esta: viver junto com os outros, chegar a Deus através do irmão (LUBICH, 2001).

5 As religiões possuem instituições fortes e potencial para liderança, provendo ao mesmo tempo autoridade moral e princípios éticos. As instituições religiosas podem ajudar a articulação de valores para um futuro sustentável, oferecendo alternativas viáveis para o materialismo, provendo sentido de vida, coerência e direção para uma agenda sustentável. - in Earth Dialogues Forum, Lyon, February 21-23, 2002 < http://www.earthdialogues.org/documents/ Synthesis.doc> visitado em 25/08/2005. 
Nesta busca de uma visão humanizada, compreende-se o homem como capaz de transformar sua realidade e implementar um saber criativo que respeita as linguagens cognitivas e inteligências emocionais. O ideal é que a pessoa seja incentivada a esta experiência religiosa e compartilhá-la na prática, buscando igualmente um equilíbrio no âmbito psíquico, o que determina uma pessoa mais feliz e completa, derivando um profissional mais competente, maleável e criativo.

\section{Considerações finais}

Em uma sociedade com ênfase extremamente competitiva, faz-se necessário que o ser retome sua própria essência a fim de não ser tragado por aquilo que o circunda. Esta essência precisa ser recuperada, perpassa em primeiro plano os aspectos emocionais do indivíduo. Esta reconstrução dos aspectos emocionais traz consigo a necessidade de reencontro com o belo, com o estético e com a seu próprio Eros, enquanto força vital. Este reencontro traz consigo a ampliação do potencial criativo, impulsionando o ser humano a produzir em sua maior capacidade. "Embora sensual e, portanto, receptiva, a imaginação estética é criadora: numa livre síntese de sua própria criação, ela constitui beleza" (MARCUSE, 1999, p. 159). O reencontro do ser humano consigo mesmo conduz a uma maior possibilidade de expansão de suas potencialidades.

Por outro lado, este reencontro consigo, se destituído de uma reconstrução relacional, apenas o conduz de volta ao individualismo destrutivo. É nesta premissa que se percebe a necessidade de um encontro com o místico e o inexplicável. Um reencontro com a religiosidade. Este reencontro não existe enquanto experiência única e destacada da realidade emocional e do belo, portanto, reencontra-se o ser humano, enquanto humano. Esta visão traz consigo a possibilidade de desenvolvimento do ser levando em conta suas múltiplas realidades, identidades e inteligências cognitivas. Em última instância, conduz o ser humano à liberdade de si próprio e à compreensão que esta liberdade deve conduzir à libertação coletiva. Um grande exemplo de possibilidade sendo posta em prática encontra-se no movimento focolares, conforme trabalhado por Chiara Lubich. Um movimento que busca pôr em prática conceitos espirituais e emocionais em um ambiente empresarial competitivo, provando ser possível a implementação de conceitos aparentemente esquecidos, como cordialidade, gentileza, gratuidade e relacionamento.

Setores empresariais ligados às áreas de atendimento ao público, criação, publicidade e demais setores em que a criatividade e amabilidade do funcionário são essenciais tornam-se os espaços onde este debate deve ser 
implementado. Demais áreas de atuação empresarial também podem beneficiar-se desta reflexão tendo como resultado ganhos significativos na qualidade de vida de seus empregados, com conseqüente melhoria na qualidade produtiva e de investimento pessoal no projeto empresarial. A partir disso, compreendem-se empresas mais humanas, onde seres humanos possam trabalhar e realizar-se.

\section{Referências}

CASTELLS, Manuel. Sociedade em rede. São Paulo, SP: Paz e Terra, 2000. CASTELLS, Manuel. 0 poder da identidade. São Paulo, SP: Paz e Terra, 2000. ELIADE, Mircéa. História das crenças e das idéias religiosas. Tomo III. Rio de Janeiro, RJ: Zahar, 1984.

BOFF, Leonardo. A águia e a galinha. Petrópolis: Vozes, 1998.

COMBLIN, José. Quais os desafios dos temas teológicos atuais? São Paulo, SP: Paulus, 2005.

MARCUSE, Herbert. Eros e civilização. Rio de Janeiro, RJ: Livros Técnicos e Científicos, 1999.

MARCUSE, Herbert. Cultura e sociedade. São Paulo, SP: Paz e Terra, 1997. v. 1. WEBER, Max. A Ética protestante e o espírito capitalista. São Paulo, SP: Martin Claret, 2003.

ALVES, Rubem. O que é religião. São Paulo, SP: Brasiliense, 1989.

MANGELOJA, Esa. Economic growth and religious production efficiency, Finlandia: University of Jyväskylä, [S.d.].

EARTHDIALOGUES. Disponível em: <http://www.earthdialogues.org/ documents/Synthesis.doc>. Acesso em: 12 maio 2005.

INCONTRI, Dora. 0 ensino inter-religioso, como fazer?. Disponível em: $<$ http://www.hottopos.com>. Acesso em: 12 maio 2005.

LUBICH, Chiara. La dottrina spirituale. Entrevista concedida a Sérgio Zavoli. Tradutor Vito Mancuso. Teatro Quirino (Roma), 3 dicembre 2001. Trascrizione del video $\mathrm{n}^{\circ} 1558$ 